\title{
Trends in STEM/STEAM Education and Students' Perceptions in Japan
}

\author{
Takuya Matsuura | ORCID: 0000-0002-7202-0428 \\ Corresponding author, \\ Graduate School of Humanities and Social Sciences, Hiroshima University, \\ 7398524 Higashi-Hiroshima, Japan \\ takuyam@hiroshima-u.ac.jp \\ Daiki Nakamura | ORCID: 0000-0002-0625-6918 \\ Graduate School of Education, Hiroshima University, 7398524 \\ Higashi-Hiroshima, Japan \\ turidaiki@shirt.ocn.ne.jp
}

Received: 18 February 2021 | Revised: 28 April 2021 | Accepted: 1 May 2021

\begin{abstract}
This study aimed to examine the trends in grants for STEM/STEAM education in Japan as well as Japanese students' perception of science learning and future careers. The grants were addressed through analysis of chronological trends, while student perceptions were reviewed through student questionnaires on Trends in International Mathematics and Science Study (TIMSS) 2011, 2015, and 2019. The results reflect ideas on not only STE M education, which is often treated in the context of workforce development and science/mathematics education in Japan, but also ideas on the rapid expansion of and changes to STEAM education around 2015, which seems to be intended the integration of multiple subjects. In contrast, the results showed that students' perceptions of science and engineering careers are improving, but there are still challenges. Since subject-integrated learning has already been conducted in Japan, we consider the further discussion required regarding specific objective of STEAM versus STE M education.
\end{abstract}

\section{Keywords}

STEM/STEAM education in Japan - integration - trend of grants - TIMSS

(C) MATSUURA AND NAKAMURA, 2021 | DOI:10.1163/23641177-BJA10022

This is an open access article distributed under the terms of the CoGn BY 4tolicense. Brill. com04/26/2023 11:47:30AM 
In the early 2010s, science, technology, engineering, and math (STEM) education, which was becoming more popular in the United States, was reported in Japan and has attracted attention in both the context of workforce development in science and engineering (e.g., Chida, 2013, Jan./Feb.) and the context of integrated education (e.g., Uchinokura et al., 2014). In addition, science, technology, engineering, arts, and math (STEAM) education, which adds art(s) to STEM, has been introduced, and the terms STEM and STEAM are now being used by administrative documents in the Ministry of Education, Culture, Sports, Science, and Technology (MEXT). In Japan, the workforce development with strong skills in science and engineering has been an issue for many years, and cross-curricular education has already been implemented, so efforts in and consideration of STEM education in the context of workforce development in science and engineering have more progressed than in other areas. Additionally, the significance of adding arts and the specific approaches in this subject area have not yet been discussed in depth. Therefore, in this paper, we will examine recent trends in Japan in both STEM and STEAM.

In Japan, there has been an insufficient quantity of research papers that explicitly use the keywords STEM and STEAM. In particular, there have been few papers on specific approaches and verification of effectiveness. For this reason, we decided to initially focus on trends in the award of grants for STEM/ STEAM research. In competitive grants, many themes that reflect the research trends of the time are proposed, and peer reviews between researchers are used to decide on their adoption. In addition, the development of human resources in STEM fields was an issue even before the use of the keyword STEM, and the courses of study for junior high school, which were revised in 2008 and 2017 , state that in science instruction, "students should be exposed to the fact that what they learn in science is related to various careers" (e.g., M EXT, 2008, p. 6o). Therefore, we believe that if these efforts have been successful, we will find some positive changes in the students' perceptions.

\subsection{Perceptions of STEM/STEAM Education in Japan}

In 2018, a MEXT task force in Japan on human-resource development for the new era pointed out that in senior high school education, "all students need to learn STEAM as a basis for thinking" (MEXT, 2018b, p. 13). Although the keyword "STEAM" had been used in education and research fields before this (e.g., Ando \& Kim, 2014; Yamazaki et al., 2016), since the release of this report, the keyword "STEAM" has also been used in many Japanese administrative documents. However, this report only refers to the meaning of STEAM as science, 
technology, engineering, art, and mathematics, and does not discuss how these subjects and areas are related. As for the meaning of "A" in STEAM, the report of the Central Council for Education reported in January 2021, "It is important to focus on the aspect of STEAM education that aims to develop the abilities necessary for citizens to live in a modern society where various fields of STEAM are intricately related. It is important to define and promote A of STEAM not only in the art and culture, but also in a broader scope (liberal arts) including life, economy, law, politics, ethics, etc." (pp. 56-57). Therefore, in the forthcoming Japanese educational administration, A will include a wide range of areas such as liberal arts.

U.S. trends in STEM began to be reported around 10 years ago in Japan. For example, Chida (2013, Jan./Feb.) reported that the President's Council of Advisors on Science and Technology (PCAST) published "Prepare and inspire: $\mathrm{K}-12$ education in science, technology, engineering, and math (STEM) for America's future" (Executive Office of the President, 2010) and "Engage to excel: Producing one million additional college graduates with degrees in science, technology, engineering, and mathematics" (Executive Office of the President, 2012). As these reports mentioned the importance of human-resource development related to science, technology, engineering, and mathematics, they were also introduced in terms of developing science and engineering human resources in Japan. Research on the professional development of STEM teachers in the U.S. (Kuerbis \& Revak, 2013), a case study of sTEM education in Iowa (Uchinokura et al., 2014), and science education reforms that include STEM (Gunji, 2015) were also presented, and by the mid-2010s, the term "sтем" was becoming more commonly known in Japan.

The idea of ST EM/STEAM education was noticed early on not only by science education researchers but also by technology and art education researchers in Japan. Isobe and Yamazaki (2015) investigated the state of the educational subjects of science, technology, engineering, and mathematics from the view of design and technology by conducting a field survey of U.K. and its National Curriculum. Yamazaki et al. (2016) discussed the idea of STEAM, citing Yakman (2008) and Yakman and Lee (2012), and its expansion in the United States and Korea; however, main foci were technology, engineering, and thinking processes, with minimal discussion on how to address arts in Japanese STEAM education. In terms of research based on art education, Ando and Kim (2014) summarized STEAM education in Korea and also presented a case study on the integration of science and art in elementary school.

Recently, the integration of the subjects and domains such as science, technology, mathematics, and the art(s) in the practice of STEM/sTEAM education has also been considered. Munegumi (2019) discusses the levels of integration 
in each subject/domain as well as the historical trends in STEM/STEAM education in the United States. He illustrated three levels of integration in STEM: separated STEM, related STEM, and integrated sтем. He also explained the ideas of Moore and Smith (2014) that there are two types of integration in STEM: context and content integration. Regarding STEAM, he cites Yakman (2008), Maeda (2013), and Korean trends and practices (Ando \& Kim, 2014) in his explanation. In addition, Tsujiai and Hasegawa (2020) pointed out that the concept of A in STEAM education is a mixture of art and arts in our country's educational policy documents. Researchers who conceptualize A as art (Liao, 2016; Maeda, 2013) explain that they focus on the contrast in thinking in STEM and art and expect educational effects such as the creation of innovation through the interaction between these differences. On the other hand, researchers who conceptualize A as the arts (Yakman, 2008) explain that they expect cross-disciplinary education to result in overall educational effectiveness. Thus, in Japan, the difference between STEM and STEAM has been discussed while referring to research in foreign countries. However, even though STEAM is understood as STEM plus A, and these are often described together as STEM/STEAM, there is still insufficient common understanding of $A$ and the differences between the two.

\subsection{Overview of Integrated Learning in Japanese Schools before STEM/STEAM}

Within the integration of subjects in modern Japanese school education, there is the experience of establishing living environment studies as a subject. We also have the experience of establishing a period for integrated studies as an approach to integrated learning. Table 1 describes the brief framework of integrated subjects and learning in Japan during the last three decades.

Living environment studies is a compulsory subject for first and second graders newly established in the 1989 revised course of study for elementary schools (Ministry of Education, 1989) and is an integration of the previously studied science and social studies. The objective of this subject is "to develop the interest in the relationship between oneself and neighboring people, societies, and nature through specific activities, to make students think about themselves and their own lives, and in the process, to help them acquire the habits and skills necessary for daily life and develop a foundation for self-reliance." (Ministry of Education, 1989, section 2.5) and is also required to enhance the effectiveness of instruction by integrating it with other subjects such as Japanese language, music, and art and crafts. Living environment studies is unique in that it emphasizes the importance of awareness, such as noticing seasonal changes, animal growth, and personal development, as well as understanding that the 
TABLE 1 History of integrated subjects and learning in Japan during the last three decades

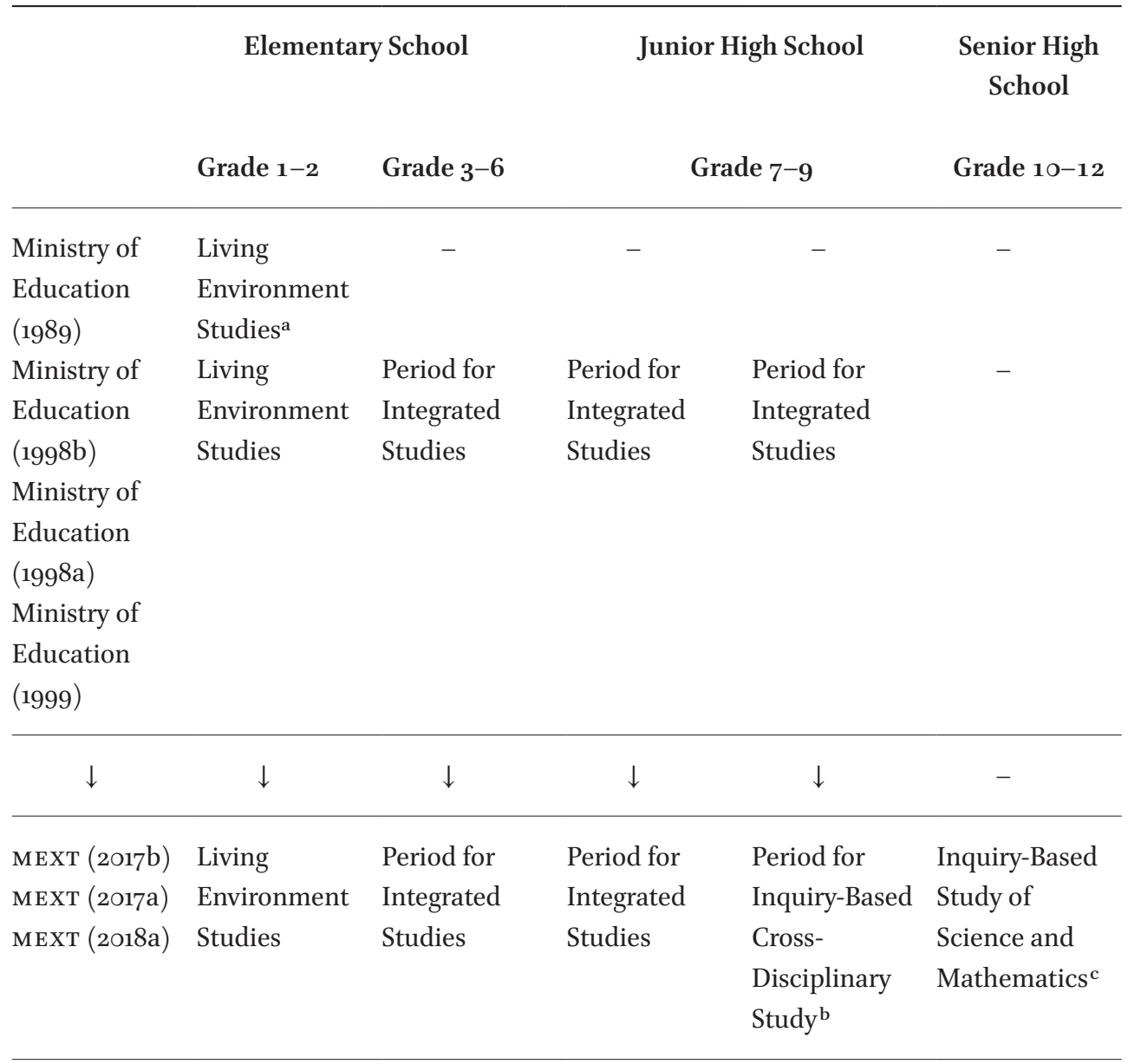

\section{Notes.}

a "Living Environment Studies" is integrated subject of Science and Social Studies.

b "Period for Inquiry-Based Cross-Disciplinary Study" is renamed from "Period for Integrated Studies".

c "Inquiry-Based Study of Science and Mathematics" is the elective subject area that includes two subjects.

* The Ministry of Education was reorganized into the Ministry of Education, Culture, Sports, Science and Technology (MEXT) in 2001.

support of many people is necessary for personal development. However, it includes both science- and social studies-based units, so the competence of the classroom teacher is required to integrate these at the class level.

Period for integrated studies is compulsory learning established in the courses of study for elementary and junior high schools revised in 1998 (Ministry of Education, 1998a, 1998b) and in the courses of study for senior 
high schools revised in 1999 (Ministry of Education, 1999). It differs from existing subjects in that it is an integrated learning activity that is not graded in the assessment of each grade. In period for integrated studies, each school is required to develop original and creative educational activities, such as crossdisciplinary and integrated learning and learning based on students' interests and concerns, according to the local area, school, students' conditions, and other considerations. However, unlike other subjects, each school has complete autonomy in selecting the content of the curriculum. Consequently, a variety of learning programs have been organized for this study, including environmental education (Ichikawa, 2007), food education (Suzuki, 2005), and community planning (Tasaka et al., 2003).

Moreover, in the 2018 revision of the courses of study for senior high schools (MEXT, 2018a), a new elective subject, inquiry-based study of science and mathematics was established. The objective of this subject is to "develop the abilities necessary to solve problems through the process of inquiry by combining mathematical and scientific approaches to various topics" (p. 196) and it aims to apply science and mathematics in an integrated way. Inquiry-based research, which had been included using the framework of science, has been reorganized as a new subject intended for integrated learning with mathematics, which we consider to be an attempt to emphasize sTEM education in Japan.

\subsection{Needs for a STEM-Capable Citizenry, a STEM-Proficient Workforce, and Future STEM Experts}

The report submitted to President Obama, which was one of the triggers for the strong support of SтEM education in the United States, states that "it is important to note that the problem is not just a lack of proficiency among American students; there is also a lack of interest in STEM fields among many students" (Executive Office of the President, 2010, p. 2). This report lists seven recommendations to improve STEM education and foster a STEM-capable citizenry, a STEM-proficient workforce, and future STEM experts. The need for a sTEM-proficient workforce and future STEM experts has also been an issue in Japan for the past three decades. The Annual Report on the Promotion of Science and Technology in 1989 described difficulty in the industrial sectors in recruiting science and technology students as researchers and engineers (Science and Technology Agency, 1989), and in the 1993 Annual Report, the section on "Young People and Science and Technology" of the report indicated that young people's interest in science and technology was declining, the ratio of applicants for admission to the schools of science was stagnant, and the ratio of applicants for admission to schools of engineering, which had been increasing until 1985, was also decreasing (Science and Technology Agency, 1993). 
Thus, even in Japan, although the term "STEM" was not used, workforce development related to STEM fields has been continuously discussed and students' interest in science has been investigated (e.g., Ogura, 2008). Therefore, we suspect that when the idea of STEM education was introduced, it was easy to interpret from the perspective of workforce development. However, the concept of stEAm education, which includes A as liberal arts (e.g., Central Council for Education, 2021), may take more time to digest in Japan, where there is a history of integrated classes.

Students' attitudes toward science are continuously measured in international surveys such as the Trends in International Mathematics and Science Study (TIMss; e.g., Martin et al., 2012) and the Programme for International Student Assessment (PISA; e.g., OECD, 2007), and many secondary analyses of differences among countries, generations, and so on have been reported (e.g., Bybee \& McCrae, 2011; Olsen \& Lie, 2011; Tsai \& Yang, 2015; You et al., 2021). In these studies, science scores and attitudes toward science have been emphasized and analyzed in multifaceted ways, as Osborne et al. (2003) have noted. In particular, TIMSS differs from PISA in that each survey includes detailed student questionnaires on science and mathematics, thus enabling detailed confirmation of changes over time in each country. Therefore, using TIMss data, it is possible to analyze based on large-scale data whether there has been any change in students' perceptions, although this analysis is limited to the context of workforce development in science and engineering.

\section{$2 \quad$ Research Questions}

As mentioned in the previous section, research and discussion on STEM/ STEAM education have been expanding in Japan. However, it is difficult to objectively ascertain when the research on STEM/STEAM education in Japan began to increase and what the trends have been. STEM/STEAM education includes a broad range of subjects and domains, and its objectives are diversifying from STEM, which focuses on development of workforce, to STEAM, which focuses on fostering capable citizens living in modern society. In this study, we utilized competitive grants rather than individual research papers to objectively indicate the extent of penetration and interest in the concepts of STEM and STEAM. It is difficult to discuss the effectiveness of STEAM education because there is still a lack of research; however, since efforts are still being conducted from the perspective of fostering human resources related to STEM, such as STEM-proficient workforces and future STEM experts, which has been an issue in Japan since the 199os, the effectiveness of these efforts can 
be examined by analyzing changes in students' perceptions. In addition, Japan has a track record of introducing integrated learning, such as the aforementioned living environment studies, and period for integrated studies. Based on our experience, we would like to discuss what issues might arise when introducing STEAM education into the school curriculum. Therefore, the objectives of this study are summarized in the following two research questions.

RQ1: What trends can be observed in the award of grants for STEM/STEAM education research in Japan?

RQ2: To what extent are Japanese students' perceptions of science learning and future careers changing?

\section{3}

\section{Methods of This Study}

The Grants-in-Aid for Scientific Research (KAKEN), managed by the Japan Society for the Promotion of Science, is a major public competitive funding agency that covers a broad range of research fields. Research themes that have been supported by KAKEN since 1965 can be searched in the database maintained by the National Institute of Informatics (NII, n.d.), so we will examine the trends of research on STEM/STEAM education in Japan using the KAKEN online database. With regard to students' perceptions of learning science and their future careers, we consider that the features of Japanese students can be clarified by comparing them with students in other countries/regions. TIMss, conducted by International Association for the Evaluation of Educational Achievement (IEA), in which Japan participates, is appropriate for the analysis in this study because students' perceptions of various issues are continuously surveyed through questionnaires, rather than merely science and mathematics tests. Finally, we discuss the expected challenges for integrated STEAM education in Japan with the results from $\mathrm{RQ}_{1}, \mathrm{RQ}_{2}$, and other questions.

\subsection{Analysis Procedure for the KAKEN Database}

A preliminary search in the KAKEN database using the keywords "STEM" and "STEAM" extracted studies that included "stem cell," and "steam" referring to water vapor. In addition, it appeared that there are some studies that are related to STEAM education but are not described as STEAM education (STEAM 教育 [kyōiku], "education"), such as STEAM context. Therefore, we determined that the search keyword string should be "STEM 教育 OR STEAM 教育” and finally confirmed the number of studies on STEM/STEAM education by verifying a 
summary of selected studies. For this search, the year and research fields are not specified. According to the results of sampling on February 1, 2021, there were 1,605 studies selected from the KAKEN database which contained the research since 199o. After verifying all research summaries and other information on these studies, we identified 134 studies related to STEM/STEAM education. For the analysis, we summarized, on a yearly basis, the number of studies and the budget for studies in which the terms "STEM" and/or "steAm" are included in the titles and keywords.

\subsection{Analysis Procedure for the TIMms Database}

International surveys such as TIMSs (Martin et al., 2012) and PISA (OECD, 2007) provide raw datasets for free. In this analysis, we analyzed the items contained in the TIMSs student questionnaire (STQ). Ultimately, we chose two items included in the Students Value Science scale for the 8th grade only: "I need to do well in science to get into the university of my choice" (STQ_Univ.) and "I would like a job that involves using science." (STQ_Job), which are commonly used in TIMSS 2011, 2015, and 2019. The Students Value Science scale also includes other items such as "I think learning science will help me in my daily life" and "I need science to learn other school subjects," and the results are integrated into the Students Value Science indicator in TIMSs reports (Martin et al., 2016; Martin et al., 2012; Mullis et al., 2020). However, only specific items will be examined in this analysis because the purpose of this analysis is to provide a specific interpretation of the questionnaire items, and fewer items were included in Students Value Science scale in the 2011 survey. In addition, Asian countries/regions with high TIMss scores and the United States, which has been at the forefront of the expansion of ST EM education in recent years, will be used for comparison in this analysis. The Asian countries/regions to be compared were Hong Kong, Korea, Singapore, and Taiwan, which were ranked in the top 10 in the 8th grade science achievement in TIMSS 2011. In addition, since gender differences have been continuously discussed in TIMSS, PISA, and STEM fields (e.g., Oon et al., 2020; Wan \& Lee, 2017), this analysis will also compare this aspect with IBM SPSS ver.26 software.

\section{$4 \quad$ Findings}

\subsection{Trends in KAKEN for STEM/STEAM Education}

The number of studies on STEM/STEAM education from the KAKEN database is presented in Table 2. We found the first study took place in 2005 , but it 
included STEM only as a keyword and not the title. Five years passed before a study appeared with STEM in the title in 2011. In 2014, additional studies with STEM in their titles appeared, and the number increased in 2015. Since 2015, the number of grant-receiving studies has reached double digits, and the budget has also expanded remarkably. Most notable is 2020, which not only shows an increase from the previous year of 10 grants but also includes STEAM in as many titles as STEM. It should be noted that even though the highest number of grants were awarded in 2020, the largest budget occurred in 2017, which is due to the difference in budgets for different studies. The 2017 budget is particularly large due to two large-scale research projects (see Figure 1). Since the term Sтем had been used in the United States before the report submitted to President Obama (Hardiman \& JohnBull, 2019), we consider that the researchers who submitted the first study in which STEM was used as a keyword in 2005 were publishing in advance of the main wave of STEM popularly in the United States.

TABLE 2 Results of KAKEN database analysis

Year

$\begin{array}{lllllllllll}2005 & 2011 & 2012 & 2013 & 2014 & 2015 & 2016 & 2017 & 2018 & 2019 & 2020\end{array}$

Title

STEM

1

3

STEAM

STEM/

1

1

STEAM

Key words

\begin{tabular}{|c|c|c|c|c|c|c|c|c|c|c|c|}
\hline STEM & 1 & 2 & 4 & 4 & 5 & 10 & 8 & 12 & 14 & 10 & 15 \\
\hline STEAM & & & & & & 4 & 2 & 2 & 2 & 5 & 12 \\
\hline STEM/ & & & & 1 & & 2 & 4 & 3 & 1 & 5 & \\
\hline STEAM & & & & & & & & & & & \\
\hline $\begin{array}{l}\text { Budget } \\
\text { (JPY) } \\
\text { million }\end{array}$ & 5.85 & 18.99 & 16.38 & 23.40 & 69.42 & 109.41 & 119.99 & 199.57 & 133.00 & $90.5^{\circ}$ & 168.19 \\
\hline$n$ & 1 & 2 & 4 & 5 & 5 & 14 & 14 & 19 & 19 & 20 & 31 \\
\hline
\end{tabular}

Note. $n=134$ 


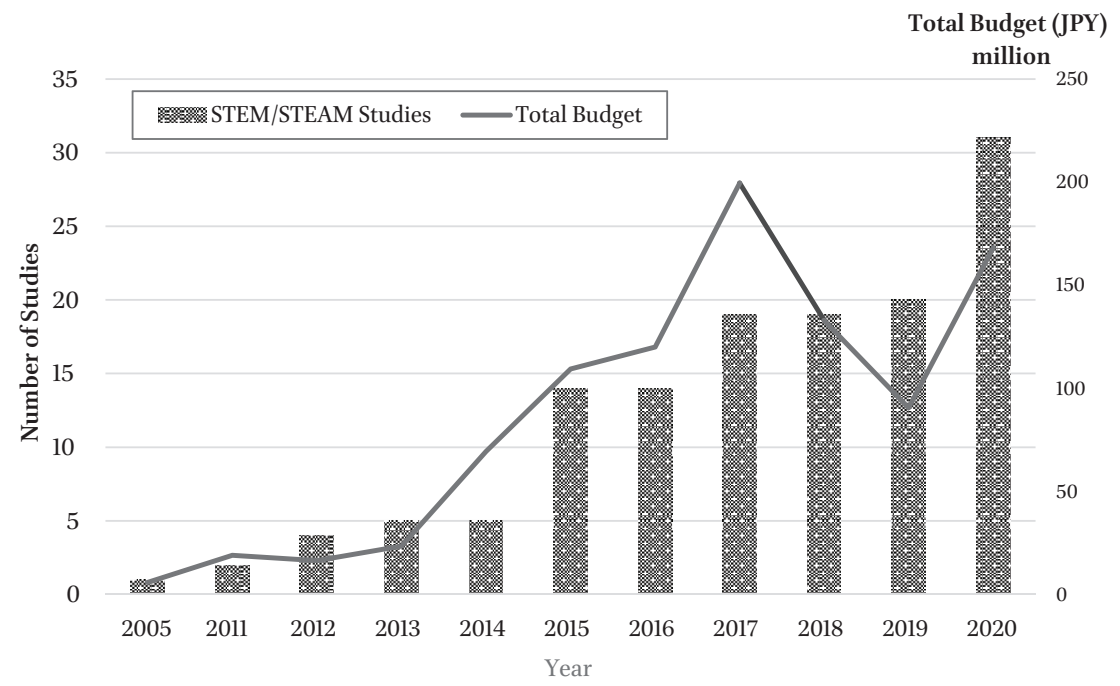

FIGURE 1 Trends of number and budget of STEM/STEAM studies

In addition, several studies extracted from the KAKEN database were analyzed qualitatively, including the research titles and their relationship to research papers. The title of the first study accepted in 2005 through STEM/STEAM research was "Development of graphics literacy curriculum" in the grant category of science education. The principal investigator of this study specialized in graphic science; therefore, he may have used the keyword STEAM in the present context. However, it appears that no research based on graphic science, including STEM/STEAM, has been adopted since then. The first study with STEM in the research title, which was adopted in 2011, was "A survey of STEM education in the U.S. and consideration for the future of science and mathematics education in Japan" in the grant category of curriculum and instruction. This study was conducted by MEXT's analyst and seems to be an analysis of STEM education in the United States from the perspective of Japanese educational administrators. Since then, the research using STEM as a keyword has expanded to diverse contexts, including science education, technology education, mathematics education, energy education, women's career development, and information and communication technology (ICT) education.

Since there were not as many studies with STEAM in the title as STEM, we selected all of them and summarized them in Table 3. The first study with STEAM, from 2015, was "Challenges and possibilities of creative education through the integration of art and science (STEAM education)" in the grant 
category of curriculum and instruction. Professor Ando, the principal investigator of this study, has been researching STEAM education in Korea since before KAKEN was adopted in 2015. Ando and Kim (2014) analyzed a Korean sixth-grade class (вовотвUG: students were asked to conceptualize a robot that could help people in the future based on insects at the water's edge, and to describe it visually) in 2012 that integrated science, home economics, and art and described the challenges from the perspective of art education. This suggests that the trend of STEAM education in Korea had been introduced before the research increased in 2015. Furthermore, four studies $(3,4,10$, and 16) are considered to be closely related to science education, accounting for about $20 \%$ of the total. Study 3 was about STEAM education in Korea with a focus on science, Study 4 addressed gifted education based on science with the intention to study STEAM education and gifted education using an interdisciplinary approach, Study 10 was conducted by a researcher who studied exhibits in a university museum designed for STEAM education, and Study 16 discussed the importance of incorporating STEAM contextual questions into problemsolving lessons. Because of the lack of information that can be extracted from the title of the research, it is impossible to be definitive, but there may not yet be enough discussion about how to place and integrate A in science-based STEAM education.

TABLE 3 Details of studies that include STEAM in their research titles

\begin{tabular}{|c|c|c|c|c|}
\hline No & Year & Grant research field & $\begin{array}{l}\text { Field of principal } \\
\text { investigator }\end{array}$ & Research title \\
\hline 1 & 2015 & $\begin{array}{l}\text { Curriculum \& } \\
\text { Instruction }\end{array}$ & Art & $\begin{array}{l}\text { Challenges and possibilities } \\
\text { of creative education } \\
\text { through the integration of } \\
\text { Art and Science (STEAM } \\
\text { education) }\end{array}$ \\
\hline 2 & 2016 & Science Education & Technology & $\begin{array}{l}\text { International comparison of } \\
\text { Mint, STEM and STEAM } \\
\text { education focused on learning } \\
\text { process }\end{array}$ \\
\hline 3 & 2016 & $\begin{array}{l}\text { Curriculum \& } \\
\text { Instruction }\end{array}$ & Science & $\begin{array}{l}\text { Research of STEAM and the class } \\
\text { activities on science curriculum } \\
\text { in Korea }\end{array}$ \\
\hline
\end{tabular}


TABLE 3 Details of studies that include STEAM in their research titles (cont.)

No Year Grant research field $\begin{aligned} & \text { Field of principal Research title } \\ & \text { investigator }\end{aligned}$

$42017 \quad$ Science Education Science

An interdisciplinary study on STEAM Gifted education curriculum considering gender and regional disparities

$5 \quad 2018 \quad$ Curriculum \& $\quad$ Technology Measuring the effectiveness of Instruction STEAM education for exploring and learning physical concepts with small computers and robotic materials

$6 \quad 2018 \quad$ Educational $\quad$ ICT Development of STEM/STEAM Technology education and teacher training system focused on subject goal and information literacy

$72019 \quad$ Curriculum \& $\quad$ Art Instruction Teaching development to ensure the uniqueness of Japan based on the consideration of STEAM education from the perspective of Arts.

$82020 \quad$ Curriculum \& $\quad$ Mathematics Development and practice of Instruction new STEAM teaching materials for oligomics covering "Basic Inquiry-Based Study of Science and Mathematics" in high school

$92020 \quad$ Curriculum \& $\quad$ Technology Development of STEAM teaching materials for younger students using thermochromic paints $10 \quad 2020 \quad$ Museology Biology Proposal of STEAM education based on interactive exhibits at science and engineering university museum

$112020 \quad$ Science Education Infant Study of STEAM education to foster competence to maintain and improve one's own health from early childhood 
TABLE 3 Details of studies that include STEAM in their research titles (cont.)

\begin{tabular}{|c|c|c|c|c|}
\hline No & Year & Grant research field & $\begin{array}{l}\text { Field of principal } \\
\text { investigator }\end{array}$ & Research title \\
\hline 12 & 2020 & Science Education & Mathematics & $\begin{array}{l}\text { Development of STEAM } \\
\text { education curriculum based on } \\
\text { Mathematics and Art and its } \\
\text { teaching model }\end{array}$ \\
\hline 13 & 2020 & Science Education & Technology & $\begin{array}{l}\text { Curriculum development for } \\
\text { STEAM education to foster } \\
\text { innovation skills with UX } \\
\text { design }\end{array}$ \\
\hline 14 & $2 \mathrm{O} 2 \mathrm{O}$ & $\begin{array}{l}\text { Curriculum \& } \\
\text { Instruction }\end{array}$ & Art & $\begin{array}{l}\text { Development of a curriculum } \\
\text { model of STEAM program based } \\
\text { on the visual literacy in Art }\end{array}$ \\
\hline 15 & 2020 & $\begin{array}{l}\text { Educational } \\
\text { Technology }\end{array}$ & $\mathrm{ICT}$ & $\begin{array}{l}\text { Design and teacher training } \\
\text { for Scratch programming } \\
\text { learning in elementary and } \\
\text { junior high schools to realize } \\
\text { STEAM education }\end{array}$ \\
\hline 16 & 2020 & Science Education & Science & $\begin{array}{l}\text { Designing a problem-solving } \\
\text { classroom model driven by } \\
\text { personal, regional, global and } \\
\text { STEAM contextual questions }\end{array}$ \\
\hline 17 & $2 \mathrm{O} 2 \mathrm{O}$ & Science Education & Technology & $\begin{array}{l}\text { New approaches to wood } \\
\text { processing lesson by developing }\end{array}$ \\
\hline 18 & 2020 & $\begin{array}{l}\text { Educational } \\
\text { Technology }\end{array}$ & ICT & $\begin{array}{l}\text { STEAM teaching materials that } \\
\text { utilize the diversity of material } \\
\text { properties of each species } \\
\text { Construction and evaluation of } \\
\text { STEAM education curriculum } \\
\text { integrating Inquiry, problem } \\
\text { solving, and design activities }\end{array}$ \\
\hline
\end{tabular}

\subsection{Students' Perceptions of Science Learning and Future Career Opportunities}

The trend of agreement for Students Value Science items from STQs with TIMSS Science Scores are presented in Table 4, and a comparison of these 
items by gender is presented in Table 5 . The findings indicate that the percentage of agreement with "I need to do well in science to get into the university of my choice" (STQ_Univ.) was larger than for "I would like a job that involves using science" (sTQ_Job) in all countries/regions. East Asian countries such as Japan, Korea, and Taiwan also tended to have a lower percentage of agreement with STQ_Univ. and STQ_Job compared to other Asian countries/regions and the United States. Elsewhere, the United States tends to have lower science scores than Asian countries, but the percentage of agreement with STQ_Univ. and STQ_Job tends to be high. Although the 2010 report by PCAST (Executive Office of the President, 2010) raised the issue of low interest of U.S. students in STEM fields, in TIMSS 2011, 81.3\% of students responded positively in STQ_Univ. and 50.8\% in STQ_Job. This is the second highest value among the six countries/regions, after Singapore. Although we cannot know how the students in the United States and elsewhere have fared in their subsequent careers, we think it will be important to compare with the United States, not only in terms of the trends described in reports, but also in terms of specific data. In addition, focusing on the trend over years, in East Asian countries/ regions including Japan, there is a slight upward trend in both STQ_Univ. and STQ_Job, but especially in Japan, STQ_Job is still low at $26.6 \%$ in 2019. Therefore, while the context of subject-integrated education is critical, we argue that it will be also critical to continue STEM education in the context of career development.

The gender differences in STQ_Univ. are larger in Japan, Korea, and Taiwan than in other countries/regions, and the volume of agreement tends to be larger in boys (Table 5). In the United States, however, the gender gap is very small. STQ_Job showed that boys tended to have a percentage of agreement that was larger by more than 10 percentage points in all Asian countries/regions, while boys in the United States only agreed 3 to 6 percentage points more than girls. However, the trends over years show no distinct decreases in gender gaps. As before, the gender gap was also mentioned as part of challenges in the 2010 PCAST report (Executive Office of the President, 2010), but at least in terms of the construct Students Value Science, this gap was already smaller than in Asian countries/regions as of TIMSS 2011. The items dealt with in this analysis are only based on the context of workforce development in science and engineering. However, since we have identified gender gaps of about 10 to 20 percentage points in Japan and other Asian countries/regions, it is necessary to monitor whether such gender gaps are also observed in subject-integrated education. However, further discussion is needed on what indicators should be used for this purpose. 
TABLE 4 Trend of students value science and science score on TIMSs, 8th grade

Year Hong Kong Japan Korea

Volume of Agree $(\%)^{\mathrm{a}}$, [95\% CI ]

$\begin{array}{lllll}\text { STQ_Univ. }^{\text {b }} & 2 \mathrm{O} & 70.6[70.3,70.9] & 58.5[58.4,58.6] & 62.6[62.4,62.7] \\ & 2 \mathrm{O} 15 & 70.1[69.7,70.4] & 59.2[59.1,59.2] & 65.8[65.6,65.9] \\ & 2 \mathrm{O} 19 & 70.5[70.1,70.9] & 65.0[64.9,65.1] & 68.2[68.1,68.3] \\ \text { STQ_Job }^{c} & 2 \mathrm{O} & 48.9[48.5,49.2] & 20.3[20.2,20.4] & 30.0[29.9,30.1] \\ & 2015 & 54.0[53.6,54.4] & 24.6[24.5,24.7] & 28.8[28.7,28.9] \\ & 2019 & 55.7[55.3,56.1] & 26.6[26.5,26.7] & 30.6[30.5,30.8]\end{array}$

Science Score

$\begin{array}{llll}2011 & 535 & 55^{8} & 560 \\ 2015 & 546 & 571 & 55^{6} \\ 2019 & 504 & 570 & 561\end{array}$

Notes.

a Volume of agree indicates the percentage of students' answer that sum of 'Agree a lot' and 'Agree a little', for each questionnaire item.

b Questionnaire for students "I need to do well in science to get into the university of my choice."

c Questionnaire for students "I would like a job that involves using science."

TABLE 5 Trend of students value science by gender on TIMSs, 8th grade

\begin{tabular}{lllll} 
Year & Gender & Hong Kong & Japan & Korea \\
\hline \multicolumn{2}{l}{$\begin{array}{l}\text { Volume of Agree }(\%)^{\text {a }} \text {, }[95 \% \text { CI }] \\
\text { STQ_Univ. } \\
2011\end{array}$} & & & \\
& Boys & $71.9[71.4,72.4]$ & $65.0[64.8,65.1]$ & $67.6[67.4,67.8]$ \\
2015 & Girls & $69.3[68.8,69.8]$ & $52.0[51.8,52.1]$ & $57.9[57.7,58.1]$ \\
& Boys & $73.2[72.7,73 \cdot 7]$ & $65.6[65.4,65 \cdot 7]$ & $69.5[69.3,69.6]$ \\
2019 & Girls & $66.7[66.1,67.2]$ & $53.0[52.9,53.1]$ & $61.7[61.5,61.8]$ \\
& Boys & $72.6[72.1,73.1]$ & $69.1[69.0,69.2]$ & $72.2[72.1,72.4]$ \\
STQ_Job ${ }^{c}$ & Girls & $68.1[67.5,68.7]$ & $61.1[61.0,61.3]$ & $63.8[63.6,64.0]$ \\
2011 & & & & \\
& Boys & $54.9[54.4,55.4]$ & $25.8[25 \cdot 7,26.0]$ & $37.5[37.3,37.6]$ \\
& Girls & $42.7[42.2,43.2]$ & $14.7[14.7,14.8]$ & $23.0[22.9,23.2]$
\end{tabular}




\section{$\begin{array}{lll}\text { Singapore } & \text { Taiwan } & \text { United States }\end{array}$}

$\begin{array}{lll}85.7[85.4,86.0] & 46.5[46.3,46.7] & 81.3[81.3,81.3] \\ 85.9[85.6,86.2] & 46.4[46.2,46.6] & 80.8[8 \circ .8,80.8] \\ 84.1[83.8,84.5] & 52.6[52.4,52.8] & 77.6[77.6,77 \cdot 7] \\ 59.9[59.5,60.3] & 25.5[25.4,25 \cdot 7] & 50.8[50.7,50.8] \\ 62.0[61.5,62.4] & 29.2[29.0,29.4] & 57.5[57.4,57.5] \\ 66.6[66.1,67.1] & 35.2[35.0,35 \cdot 5] & 56.1[56.0,56.1]\end{array}$

$\begin{array}{lll}590 & 564 & 525 \\ 597 & 569 & 530 \\ 608 & 574 & 5^{22}\end{array}$

$\begin{array}{lll}86.3[85.8,86.7] & 49.1[48.8,49.3] & 82.1[82.1,82.2] \\ 85.2[84.7,85.6] & 43.8[43.5,44.0] & 80.5[80.4,80.6] \\ 87.4[87.0,87.8] & 49.3[49.0 .49 .5] & 81.5[81.5,81.6] \\ 84.3[83.8,84.8] & 43.4[43.1,43.6] & 80.1[80.0,80.1] \\ 84.7[84.2,85.2] & 57.2[56.9,57.5] & 77.7[77.6,77.8] \\ 83.5[83.0,84.0] & 48.0[47.7,48.3] & 77.6[77.5,77 \cdot 7] \\ & & \\ 64.5[64.0,65.1] & 33.5[33.2,33.7] & 52.4\left[5^{2.3}, 52.5\right] \\ 55.1[54.5,55.7] & 17.1[16.9,17.3] & 49.2[49.1,49.3]\end{array}$


TABLE 5 Trend of students value science by gender on TIMSs, 8th grade (cont.)

\begin{tabular}{cllll}
\hline Year & Gender & Hong Kong & Japan & Korea \\
\hline \multirow{2}{*}{2015} & Boys & $61.4[60.9,62.0]$ & $31.2[31.1,31.3]$ & $36.7[36.5,36.8]$ \\
& Girls & $45.8[45.2,46.4]$ & $18.3[18.2,18.4]$ & $20.1[19.9,20.2]$ \\
2019 & Boys & $62.7[62.1,63.2]$ & $33.0[32.9,33.2]$ & $39.4[39.2,39.6]$ \\
& Girls & $47.7[47.1,48.3]$ & $20.6[20.5,20.7]$ & $21.2[21.0,21.4]$ \\
\hline
\end{tabular}

Notes.

a Volume of agree indicates the percentage of students' answer that sum of 'Agree a lot' and 'Agree a little', for each questionnaire item.

b Questionnaire for students "I need to do well in science to get into the university of my choice."

c Questionnaire for students "I would like a job that involves using science."

\section{$5 \quad$ Discussion}

5.1 Trends of STEM/STEAM Education and Future Directions in Japan

Our research, through KAKEN for STEM/STEAM education, and trends in studies and reports on STEM/STEAM education, and their treatment in MEXT, revealed a variety of trends suggesting a significant increase in STEM/STEAM interest over the past decade. The large increase in the number of grants seen in KAKEN in 2015 suggests that global interest in STEM/STEAM education existed by at least the fall of 2014 (most KAKEN proposal deadlines are typically scheduled in the fall of the previous year). As mentioned in the introduction, trends in U.S. STEM education began to appear in public reports and academic journals around 2013 in Japan (Chida, 2013, Jan./Feb.; Kuerbis \& Revak, 2013; Uchinokura et al., 2014), and trends in STEAM education in Korea and other countries began to be reported around 2014 (Ando \& Kim, 2014). As for STEAM education, since the number of occurrences of the keyword increased in 2019 and in research titles in 2020, we consider that the release of MEXT (2018b) and the usage of the term "STEAM" in various administrative documents also had an impact.

Even in STEM education, which has a longer history than STEAM education, some issues such as "recent research has revealed considerable confusion, misunderstanding, and variance in how educators view STEM teaching and learning" (Sgro et al., 202O, p. 185) have been raised in recent years. Becker \& Park (2011) also report that, out of 28 empirical studies of STEM education, 17 integrated across only two of the four (science, technology, engineering, and 


$\begin{array}{lll}\text { Singapore } & \text { Taiwan } & \text { United States } \\ 67.5[66.9,68.1] & 38.1[37.9,38.4] & 60.4[60.3,6 \circ .4] \\ 56.1[55.5,56.7] & 19.8[19.6,20.0] & 54.7[54.6,54.7] \\ 71.8[71.1,72.4] & 44.9[44.6,45.2] & 58.0[58.0,58.1] \\ 61.2[60.5,61.9] & 25.4[25.1,25.6] & 54.2[54.1,54.2]\end{array}$

mathematics) disciplines and only one study integrated across all four disciplines. It will be important to reach a specific consensus on how to define the meaning of "A" in STEAM education as well as practical issues of how to organize the curriculum and teach it from the perspective of STEAM education.

In addition, as stated by Isozaki (2019), who summarizes the background of sTEM education based on trends in the United States (Executive Office of the President, 2010) and the United Kingdom (The Royal Society, 2014), it is necessary to consider the importance of teacher training that will facilitate STEM/ STEAM education in near future (Maruyama et al., 2019). It also needs to take into account the differences and characteristics of school types, as Newman et al. (2020) argued the following:

While we only gained insight into the portrayal of what schools are tagging as ST EM on social and digital media, from what we can see, it appears that elementary schools try to integrate the disciplines while middle and high school grow increasingly separate discipline-wise. This could be due to the fact that elementary schools are designed in a way where one teacher is responsible for all subjects, as opposed to high school where each teacher has their own subject. (p. 182).

\subsection{How SteAm Education Can Be Applied to Student Development and Career}

In Japan, the declining interest of young people in science and technology has been a problem for a long time (Science and Technology Agency, 1993), and the 
fact that very few students demonstrated interest in science-related occupations in the PISA 2006 survey was also a serious issue. This interest increased by 5 percentage points between 2006 and 2015 based on responses to PISA 2015, but the percentage is still low at $18 \%$ (OECD, 2016). As a response to such issues at the national level, for example, the Courses of Study for Junior High Schools revised in 2008 and 2017 have aimed to link science learning to future career choices by stating in science instruction that "students should be exposed to the fact that what they learn in science is related to various careers" (e.g., MEXT, 2017, p. 98). In the TIMSS results analyzed in this study, the percentage of Japanese students' positive responses to STQ_Univ. and STQ_Job continues to be lower than that of other Asian countries/regions and the United States. Therefore, it is necessary to continue to focus on improvement. We must also continue to work on closing the gender gap, which is around 10 percentage points. The Japan Science and Technology Agency (JST) has been promoting the idea that all people, regardless of age, gender, or nationality, should respect each other's way of thinking and make the most of their respective abilities (e.g., Japan Society for the Promotion of Science, n.d.). On the other hand, the TIMSS short reports released by the National Institute for Educational Policy Research (NIER) often do not include data on gender differences (e.g., National Institute for Educational Policy Research, 2020), which makes it difficult for the public to understand how gender differences are being addressed. Ikkatai et al. (2019) reported that girls' choice of sTEM fields was affected by stereotypical parental gender role attitudes, suggesting that both students themselves and Japanese society as a whole need to change the sense of value about STEM fields. Based on the above, it is necessary to expand the discussion based on survey data such as TIMSs, not only on the ratio of female researchers whose focus is on adults, but also on gender differences in the children's stages.

What positive effects can be expected from integrated STEAM education rather than STEM education purely for career aspiration? For example, Maeda (2013) promoted STEAM education because he believed that adding art with divergent thinking to STEM subjects with convergent thinking can prompt innovations. Tohyama and Takeuchi (2018) conducted collaborative music creation activities in a STEAM framework, expecting not only to be able to create beautiful secondary melodies, but also to increase self-esteem. According to Land (2019), the push for the STEAM platform derives from a perceived shortage in creativity and innovation in recent college graduates in the United States. The idea is to expand creativity and other skills by adding art to STEM.

However, the Central Council for Education (2021) shows another way of conceptualizing A as arts (liberal arts) in Japan similar to Yakman (2008), so even if we can understand it as a philosophy, further study is required on how 
to implement it in practice. Although the specifics of integrated STEAM education are still unclear, since STEAM education in Japan may be addressed not only in the classroom during the subjects included in STEAM but also in the period for integrated studies, we believe that Japanese teachers can make use of their previous experience in creating integrated learning programs. Moreover, the evaluation of period for integrated studies is basically only making note of the activities, and no grading is given as it would be for science or mathematics. Therefore, the program must be developed with the clear objective of what kind of abilities to develop through STEAM education and also to consider and develop valid evaluation methods.

\section{Implications for STEAM Education}

This paper analyzes and discusses the chronological trends in research on STEM and STEAM education in Japan from a macro perspective. Therefore, despite insufficient understanding of the details of each study, we have provided data that indicates not only the spread of sTEM education, which is often treated in the context of career development and science/mathematics education in Japan, but also the rapid expansion of the idea of STEAM education in Japan, which seems to be intended to deal with multiple subjects and domains in integrated ways. In addition, we explained that there are multiple approaches to how to integrate the subjects and domains included in STEAM and that handling of STEAM in Japanese public education is one of the important issues to be considered in the future. Finally, the perceptions of students, who are the learners, could be examined only in the context of human-resource development and science/mathematics education. Consequently, we have identified the need for further discussion and research on what kinds of awareness need to be developed in students through STEAM education, as well as the objectives of STEAM education.

\section{7}

\section{Limitations}

Since the analysis of STEM/STEAM education grants in KAKEN focused on the titles and keywords of the studies, it was not possible to mention the details of individual studies. Therefore, further analysis is required on the specific details of STEM/STEAM education research in Japan. In addition, with regard to the analysis of IEA/TIMSS data, we focused on some questionnaire items included in the Students Value Science scale and compared the trends in the percentage 
of positive student responses. Since there are many survey items related to students' perceptions, a multidimensional analysis is required to obtain a comprehensive picture of students' perceptions.

\author{
Abbreviations \\ ICT Information and Communication Technology \\ IEA International Association for the Evaluation of Educational Achievement \\ KAKEN The Grants-in-Aid for Scientific Research \\ MEXT Ministry of Education, Culture, Sports, Science and Technology \\ NIER National Institute for Educational Policy Research \\ NII National Institute of Informatics \\ OECD Organisation for Economic Co-operation and Development \\ PISA Programme for International Student Assessment \\ STEAM Science, Technology, Engineering, Art(s), and Math \\ STEM Science, Technology, Engineering, and Math \\ TIMSS Trends in International Mathematics and Science Study
}

\title{
Funding
}

This work was supported by JSPS KAKENHI Grant Numbers JP17Hoo82O, JP19Ho1736.

\section{Ethical Consideration}

The data reported in this study does not require human subjects' approval.

\section{About the Authors}

Takuya Matsuura is an Associate Professor at the Graduate School of Humanities and Social Sciences, Hiroshima University, Japan. His research focuses on students' thinking in science learning that include reasoning, metacognition and other issues.

Daiki Nakamura is a doctoral student at the Graduate School of Education, Hiroshima University, Japan. His research focuses on hypothesis formulation in scientific inquiry and research methods in educational study. 


\section{References}

Ando, K., \& Kim, J. (2014). Exploring possibilities and problems of education by integrating science and art: Focusing on an examination of the principles and practices of STEAM education in Korea. The Journal for the Association of Art Education, 35, 61-77. https://doi.org/10.24455/aaej.35.0_61.

Becker, K., \& Park, K. (2011). Effects of integrative approaches among science, technology, engineering, and mathematics (STEM) subjects on students' learning: A preliminary meta-analysis. Journal of STEM Education, 12 (5 \& 6), 23-37.

Bybee, R., \& McCrae, B. (2011). Scientific literacy and student attitudes: Perspectives from PISA 2006 science. International Journal of Science Education, 33(1), 7-26. https://doi.org/10.1080/o9500693.2010.518644.

Central Council for Education. (2021). Reiwa no nippon gata gakkou kyouiku no kouchiku wo mezashite: Toushin [Toward the construction of "Japanese school education in the Reiwa era" (Report)]. https://www.mext.go.jp/content/20210126-mxt_syotoo2 -oooo12321_2-4.pdf.

Chida, Y. (2013, Jan./Feb.). Beikoku ni okeru kagakugijyutu jinzai ikusei senryaku [Strategies for developing human resources for Science and Technology in the U.S.]. Science \& Technology Trends, 17-26.

Executive Office of the President. (2010). Report to the president. Prepare and inspire: K-12 education in Science, Technology, Engineering, and Math (sTEM) for America's future (ED516oog). https://eric.ed.gov/?id=ED516oog.

Executive Office of the President. (2012). Report to the president. Engage to excel: Producing one million additional college graduates with degrees in Science, Technology, Engineering, and Mathematics (ED541511). https://eric.ed.gov/?id=ED541511.

Gunji, Y. (2015). Amerika no kagaku kyouiku kaikaku [Science education reform in the United States]. CHEMISTRY \& EDUCATION, 63(10), 480-483. https://doi.org/ 10.20665/kakyoshi.63.10_48o.

Hardiman, M. M., \& JohnBull, R. M. (2019). From STEM to STEAM: How can educators meet the challenge? In A. J. Stewart, M. P. Mueller, \& D. J. Tippins (Eds.), Converting STEM into STEAM programs: Methods and examples from and for education (pp. 1-10). Springer. https://doi.org/10.1007/978-3-030-25101-7_1.

Ichikawa, S. (2007). Trends of environmental education in the Period for Integrated Study in primary and lower secondary school.Journal of Science Education in Japan, 31(2), 145-149. https://doi.org/10.14935/jssej.31.145.

Ikkatai, Y., Inoue, A., Kano, K., Minamizaki, A., McKay, E., \& Yokoyama, H. M. (2019). Parental egalitarian attitudes towards gender roles affect agreement on girls taking STEM fields at university in Japan. International Journal of Science Education, 41(16), 2254-2270. https://doi.org/10.108o/o950o693.2019.1671635.

Isobe, M., \& Yamazaki, S. (2015). The current state of the educational subjects of "Science, Technology, Engineering and Mathematics" from the view of design and 
technology. Journal of Science Education in Japan, 39(2), 86-93. https://doi.org/ 10.14935/jssej.39.86.

Isozaki, T. (2019). Research on teacher education for STEM teachers and their teacher educators. Proceedings of the 43rd Annual Meeting of Japan Society for Science Education, Utsunomiya, Japan.

Japan Society for the Promotion of Science. (n.d.). Diversity. https://www.jst.go.jp/ diversity/en/index.html.

Kuerbis, P. J., \& Revak, M. D. (2013). STEM teacher development in the United States: Key research recommendations and results from a longitudinal study of K-5 science teacher development on student achievement. Journal of Science Education in Japan, 37(2), 75-87. https://doi.org/10.14935/jssej.37.75.

Land, M. (2019). The importance of integrating the arts into STEM curriculum. In A. J. Stewart, M. P. Mueller, \& D. J. Tippins (Eds.), Converting STEM into STEAM programs: Methods and examples from and for education (pp. 11-19). Springer. https:// doi.org/10.1007/978-3-030-25101-7_2.

Liao, C. (2016). From interdisciplinary to transdisciplinary: An arts-integrated approach to STEAM education. Art Education, 69(6), 44-49. https://doi.org/10.108o/ooo43125 .2016 .1224873 .

Maeda, J. (2013). STEM + Art = STEAM. The STEAM Journal, 1(1). https://doi.org/10 $.5642 /$ steam.201301.34.

Martin, M. O., Mullis, I. V. S., Foy, P., \& Hooper, M. (2016). TIMSS 2015 international results in Science. TIMss \& PIRLS International Study Center \& IEA. http://tims sandpirls.bc.edu/timss2015/international-results/wp-content/uploads/filebase/ full\%2opdfs/T15-International-Results-in-Science.pdf.

Martin, M. O., Mullis, I. V. S., Foy, P., \& Stanco, G. M. (2012). TIMSS 2011 international results in Science. TIMSS \& PIRLS International Study Center \& IEA. https://tims sandpirls.bc.edu/timss2011/downloads/T11_IR_Science_FullBook.pdf.

Maruyama, M., Nagahama, T., Kitazawa, T., Setozaki, N., \& Morita, Y. (2019). Practical study on STEM education for school teacher training course students. JSSE Research Report, 34(3), 303-308. https://doi.org/10.14935/jsser.34.3_303.

Ministry of Education. (1989). Shougakkou gakusyuu shidou youryou [Course of study for elementary schools]. Ministry of Education.

Ministry of Education. (1998a). Chuugakkou gakusyuu shidou youryou [Course of study for lower secondary schools]. Ministry of Education.

Ministry of Education. (1998b). Shougakkou gakusyuu shidou youryou [Course of study for elementary schools]. Ministry of Education.

Ministry of Education. (1999). Koutougakkou gakusyuu shidou youryou [Course of study for senior secondary schools]. Ministry of Education.

Ministry of Education, Culture, Sports, Science and Technology [MEXT]. (2008). Chuugakkou gakusyuu shidou youryou [Course of study for lower secondary schools]. Ministry of Education, Culture, Sports, Science and Technology. 
Ministry of Education, Culture, Sports, Science and Technology [MEXT]. (2017). Chuugakkou gakusyuu shidou youryou [Course of study for lower secondary schools]. Ministry of Education, Culture, Sports, Science and Technology.

Ministry of Education, Culture, Sports, Science and Technology [MEXT]. (2018a). Koutougakkou gakusyuu shidou youryou [Course of study for senior secondary schools]. Ministry of Education, Culture, Sports, Science and Technology.

Ministry of Education, Culture, Sports, Science and Technology [MEXT]. (2018b). Society 5.0 ni muketa jinzai ikusei [Human resource development for society 5.0]. https://www.mext.go.jp/component/a_menu/other/detail/_icsFiles/afieldfile/ 2018/o6/o6/1405844_0o2.pdf.

Moore, T. J., \& Smith, K. A. (2014). Advancing the state of the Art of STEM integration. Journal of STEM Education, 15(1), 5-10.

Mullis, I. V. S., Martin, M. O., Foy, P., Kelly, D. L., \& Fishbein, B. (2020). TIMSS 2019 international results in Mathematics and Science. TIMSS \& PIRLS International Study Center \& IEA. https://timssandpirls.bc.edu/timss2o19/international-results/ wp-content/themes/timssandpirls/download-center/TIMSS-2019-International -Results-in-Mathematics-and-Science.pdf.

Munegumi, T. (2019). STEM education and STEAM education: History, definition, and integration. Research bulletin of Naruto University of Education, 34, 58-72. https:// doi.org/10.24727/00028103.

National Institute for Educational Policy Research. (2020). TIMSs 2019 no point [TIMSS 2019 short report]. https://www.nier.go.jp/timss/2019/point.pdf.

Newman, S., Kahn, T., Guo, M., Gerber, A., Burgess, A., \& Akerson, V. L. (2020). Public portrayals of Indiana STEM certified schools. In V. L. Akerson \& G. A. Buck (Eds.), Critical questions in STEM education (pp. 167-184). Springer International Publishing. https://doi.org/10.1007/978-3-030-57646-2_10.

NII. (n.d.). Database of Grants-in-Aid for Scientific Research (KAKEN). https://kaken.nii .ac.jp/en/index/.

Ogura, Y. (2008). Comparison of attitudes toward science between Japanese students of grade 9 and 10 by using the PISA questions. Journal of Science Education in Japan, 32(4), 330-339. https://doi.org/10.14935/jssej.32.330.

Olsen, R. V., \& Lie, S. (2011). Profiles of students' interest in science issues around the world: Analysis of data from PISA 2006. International Journal of Science Education, 33(1), 97-120. https://doi.org/10.1080/o9500693.2010.518638.

Oon, P. T., Cheng, M. M. W., \& Wong, A. S. L. (2020). Gender differences in attitude towards science: methodology for prioritising contributing factors. International Journal of Science Education, 42(1), 89-112. https://doi.org/10.108o/09500693.2019 .1701217 .

Organisation for Economic Co-operation and Development [OECD]. (2007). PISA 2006 science competencies for tomorrow's world (Vol. 1). Organisation for Economic Co-operation and Development. 
Organisation for Economic Co-operation and Development [OECD]. (2016). Country note - Results from PISA 2015: Japan. OECD. http://www.oecd.org/pisa/PISA-2015 -Japan.pdf.

Osborne, J., Simon, S., \& Collins, S. (2003). Attitudes towards science: A review of the literature and its implications. International Journal of Science Education, 25(9), 1049-1079. https://doi.org/10.108o/o950o69o32000032199.

Science and Technology Agency. (1989). Heisei gannen ban kagaku gijyutsu hakusyo [Annual report on the promotion of science and technology 1989]. Ministry of Finance Printing Bureau. https://warp.ndl.go.jp/info:ndljp/pid/11293659/www.mext .go.jp/b_menu/hakusho/html/hpaa1989o1/index.html.

Science and Technology Agency. (1993). Heisei 5nen ban kagaku gijyutsu hakusyo [Annual report on the promotion of science and technology 1993]. Ministry of Finance Printing Bureau. https://warp.ndl.go.jp/info:ndljp/pid/11293659/www.mext .go.jp/b_menu/hakusho/html/hpaa1993o1/index.html.

Sgro, C. M., Bobowski, T., \& Oliveira, A. W. (2020). Current praxis and conceptualization of STEM education: A call for greater clarity in integrated curriculum development. In V. L. Akerson \& G. A. Buck (Eds.), Critical questions in STEM education (pp. 185-210). Springer International Publishing. https://doi.org/10.1007/ 978-3-030-57646-2_11.

Suzuki, Y. (2005). The current state of dietary education for first to fourth grade elementary students: The treatment of cooking skills in Life Environment studies, periods for integrated study, and special activities. The Bulletin of Japanese Curriculum Research and Development, 28(3), 1-8. https://doi.org/10.18993/jcrdajp.28.3_1.

Tasaka, R., Wada, O., \& Takamizawa, M. (2003). A study concerning "community planning education" built in at class of overall study of elementary school: Through the investigation intended for the elementary school in Yokohama City. Journal of the City Planning Institute of Japan, 38(3), 277-282. https://doi.org/10.11361/ journalcpij.38.3.277.

The Royal Society. (2014). Vision for science and mathematics education. https://royal society.org/-/media/education/policy/vision/reports/vision-full-report-20140625 .pdf.

Tohyama, S., \& Takeuchi, Y. (2018). Proposing a design of collaborative creative musical activity and an evaluation method as STEAM education: Focusing on changes of primary school children's self-esteem. The Transactions of Human Interface Society, 20(4), 397-412. https://doi.org/10.11184/his.20.4_397.

Tsai, L.-T., \& Yang, C.-C. (2015). Hierarchical effects of school-, classroom-, and student-level factors on the science performance of eighth-grade Taiwanese students. International Journal of Science Education, 37(8), 1166-1181. https://doi.org/ 10.1080/09500693.2015.1022625. 
Tsujiai, H., \& Hasegawa, H. (2020). A study of the concept of "A" in STEAM education. Journal of Science Education in Japan, 44(2), 93-103. https://doi.org/10.14935/ jssej.44.93.

Uchinokura, S., Ishizaki, T., Saito, T., Irma, R. S., Imamura, T., Kumano, Y., \& Nagasu, N. (2014). A report for examples of STEM education promotion in United States: A focus on practical efforts in state of Iowa. JSSE Research Report, 29(1), 87-92. https://doi.org/10.14935/jsser.29.1_87.

Wan, Z. H., \& Lee, J. C. K. (2017). Hong Kong secondary school students' attitudes towards science: A study of structural models and gender differences. International Journal of Science Education, 39(5), 507-527. https://doi.org/10.108o/o9500693.2017 .1292015 .

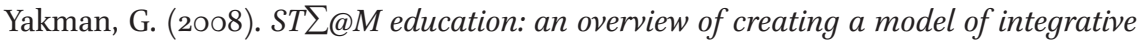
education. https://steamedu.com/wp-content/uploads/2014/12/20o8-PATT-Publica tion-STEAM.pdf.

Yakman, G., \& Lee, H. (2012). Exploring the exemplary STEAM education in the U.S. as a practical educational framework for Korea. Journal of the Korean Association For Research in Science Education, 32(6), 1072-1086. https://doi.org/10.14697/ JKASE.2012.32.6.1072.

Yamazaki, S., Oomori, Y., \& Isobe, M. (2016). The interpretation of elementary school textbooks as authorized teaching matters from the viewpoint of STEM/STEAM education. Bulletin of Joetsu University of Education, 36(1), 209-215.

You, H. S., Park, S., \& Delgado, C. (2021). A closer look at US schools: What characteristics are associated with scientific literacy? A multivariate multilevel analysis using PISA 2015. Science Education, 105(2), 406-437. https://doi.org/https://doi.org/ 10.1002/sce.216o9. 